\title{
Sustainable income: reflections on the valuation of nature in environmental- economic accounting
}

\author{
Walter Radermacher \\ Statistisches Bundesamt Abt. IV, D-65180 Wiesbaden, Germany
}

\begin{abstract}
A standard demand made in connection with structural economic reform, ecological tax reforms and the like is that national product computation be corrected in order to obtain a 'Green GDP'. Prices ought no longer to 'tell the truth' only in individual cases but also at the macroeconomic level, and take into account the scarcity of natural resources. This contribution analyses the chances of meeting this demand in practice. It is shown that the opportunities of obtaining information and the knowledge available are so limited that the statistical implementation of theoretical models has not been successful. This means that the informational problem is no longer a marginal issue but of a central nature and must influence the way theoretical models are set up.
\end{abstract}

\section{Preliminary Note}

'I know not when we shall have a perfect system of statistics, but the want of it is the only insuperable obstacle in the way of making Political Economy an exact science'. With this statement, made nearly seventy years ago, W.St. Jevons already deplored the lack of empirical implementation of economic theories [1]. Although much has changed since within the system of statistics, there are still spheres in which only insufficiently quantified knowledge is available. One of these spheres is the relation between human activities and their impact on nature.

The attempt to develop this sphere by empirically covering and including it in the existing systems of economic reporting and analysis is the subject and purpose of Environmental-Economic Accounting (Umweltökonomische Gesamtrechnung UGR)*. While the framework concept and the projects of the current UGR programme of work were presented in earlier papers $[2,37,38]$, this contribution will examine more closely the question of a possible valuation and the establishment of a highly aggregated economic indicator ('Green National Product'). It turns out here that the opposite of Jevons' statement is true: Empirical evidence - or the lack of it does not impede the development of a scientific economic theory. On the contrary: so far, there have not been any feasible models or practicable approaches to this complex of novel problems.

* by the Federal Statistical Office of Germany. 
Sustainability is currently the keyword in the political discussion of environmental issues. Therefore, sustainability will be the starting point for a discussion about implementing economic theories and, above all, the question of evaluating environ. mental burdens and environmental protection within the scope of UGR.

\section{Defining Sustainability}

Sustainability is a 'term from agriculture and forestry referring to a way of managing which ensures that the output level of the ecosystem will be completely sustained for future generations. There is no uniform use of the term; it may refer to sustaining the wooded area, the yield of wood, the value added of the agricultural holding or the ecological balance' cf. [3].

As far as the term 'sustainable development' [4] is concerned, one might as well do without explicitly mentioning 'development', as it is implicitly included in the definition of sustainability.

Sustainable development is to preserve the bases, the capital of the developmerit. Not managing in a sustainable way means living beyond one's means and jeopardizing one's future prosperity or even one's future existence. Development in this context means a set of objectives [5], such as:

- growth of the per capita income in real terms,

- improving public health systems, nutrition and the educational system,

- availability of resources,

- levelling differences in income,

- safeguarding basic rights.

A development is 'sustainable' if it does not become negative in the course of time. There is a further distinction between strict sustainability where the above condition applies to all periods, and weak sustainability where the trend or the present value of the development vector must be above zero.

Actually, this target value is not strange or novel to economics: Hicks, for instance, defines 'a man's income as the maximum value which he can consume during a week, and still expect to be as well off at the end of the week as he was at the beginning' [6]. In this sense, the term 'income' includes sustainability. It is just required to consider the natural resources as sources of income.

On the basis of this reflection, it should be discussed what consequences can be derived for the capital of nature. Does 'natural capital' have to be (at least) constant, and is it thus the status quo that has to be sustained? Or is the objective the maximum efficiency of natural capital in the sense of a cost-benefit analysis? Pearce arrives at the conclusion that a combination of the two objectives should be aimed at, that is, an optimization of efficiency on the condition that the status quo be sustained. Problems of quantification, in particular of the benefit side, make it seem doubtful to him that the objective of efficiency alone will ensure future existence. Even the aim of sustaining the capital, however, still has to be specified with regard to its measurement: should the capital physically/qualitatively remain constant; should its economic value be constant; can prices serve as indicators of scarcity; should it be possible to 
substitute natural capital by economic capital?

As was shown by the reservation expressed in the above-quoted definition, sustainability is not a term which might be described as a generally accepted convention. It can rather be observed on closer examination that, although this topical keyword is used by everyone, it is used to mean very different things when it comes to the details. However, the fact that this keyword has been included in the various action programmes at both international and national level shows that it has been managed to make the general public aware of the interconnections between development and environmental policies, between growth and consumption of natural resources, etc. It should be kept in mind that 'sustainable development' is a normative political value serving as an orientation and a target whose meaning has to be discussed and defined in detail.

\section{Interpreting Sustainability}

\subsection{Magnitudes of Environmental Problems}

It is remarkable that, in the discussion of environmental problems, people refer in the same breath to examples of quite different magnitudes. Often no differentiation is made between issues that relate to a small region - which have to be settled by the polluters and persons affected who live in that region - and others where the group or region concerned is large, very large or even global. In a similar way, this is true of the lapse between cause and effect. Such magnitudes are, however, just as important for the assessment of an environmental phenomenon as for its cure. In analogy to the well-known classification of military matters, Gore [7] suggests a distinction between local, regional and global problems of the environment. In particular the global environmental problems, such as the greenhouse effect, the hazards of nuclear energy, or the extinction of species are spheres showing an urgent need for action from the point of view of sustainability. It is, however, precisely these spheres that involve great difficulties both with regard to diagnosis and to therapy [8]. The following explanations should be considered in particular from this aspect.

\subsection{Interpreting Sustainability with Regard to Different Interests}

The way someone understands and interprets the objective of sustainability relects his or her socio-political, economic or scientific position [9]. The different viewpoints may be illustrated by means of the following division of environmental burdens into components:

$$
U=A \cdot k \cdot e
$$

with: $U$ : Total environmental pressure,

$A:$ Number of human actors,

$k$ : Level of activity per person,

$e$ : Emissions per activity unit. 
Industrialized nations contribute to the consumption of natural resources mainly by their level of activity per person, i.e., a level of activity that is considerably higher than the global average, while their populations stagnate and the technologies used are already advanced in many fields in terms of environmentally friendly procedures. In developing countries, the causes of environmental pollution, consumption of resources, etc., are great numbers of inhabitants, rapid population growth and underdeveloped technology.

A global environmental policy thus has to start especially at those weak points. If the connection between poverty and population growth in developing countries is included in the considerations, it becomes obvious how close the interrelationship between problems of development and environment really is [10]. This diagnosis was consistently implemented when the United Nations organized a joint Conference on Environment and Development (UNCED) in Rio de Janeiro in 1992. However, that conference also revealed that implementing relevant programmes is extremely difficult since the interests of industrialized and developing countries are diametrically opposed.

The opinion is still widespread in industrialized countries that the contribution to environmental protection should consist in technological innovation, that is, in forming 'restoration assets' [11] - meaning that, for instance, growing individual traffic could be rendered environmentally compatible by employing filters and catalytic converters. These interpretations of sustainability do not aim at limiting prosperity and growth in quantity. Does this mean that a solution of the much-quoted conflict between economy and ecology has come within easy reach through environmental marketing, eco-auditing, life-cycle analysis or technological developments? Is growth perhaps even a prerequisite for financing environmental protection measures? And, finally, is environmental protection for this reason feasible only at times of economic boom?

These questions go straight to the core of a discussion that has been going on since the 1970s and is highly emotional [12]. It appears all the more important to find out how much leeway there is and to provide information for practical policies. Here is an example: An important question in this connection is, among others, to what extent growth results from an increased production of commodities and of services, respectively. So economic growth can also be environmentally compatible where it does not involve a higher consumption of raw materials or a higher emission of pollutants. Thus, a structural change towards a 'service economy' can, under certain conditions, create important leeway for action. As regards a structural change towards the 'service economy', which obviously is considered to be more positive in ecological terms, it must be examined whether, and to what extent, changes of location occur or have occurred in production industries and whether or not the service economy induces a specific consumption of resources [13]. For sectoral economic and environmental policies it is therefore important to know which environmental burdens are due to economic growth in the different branches. 


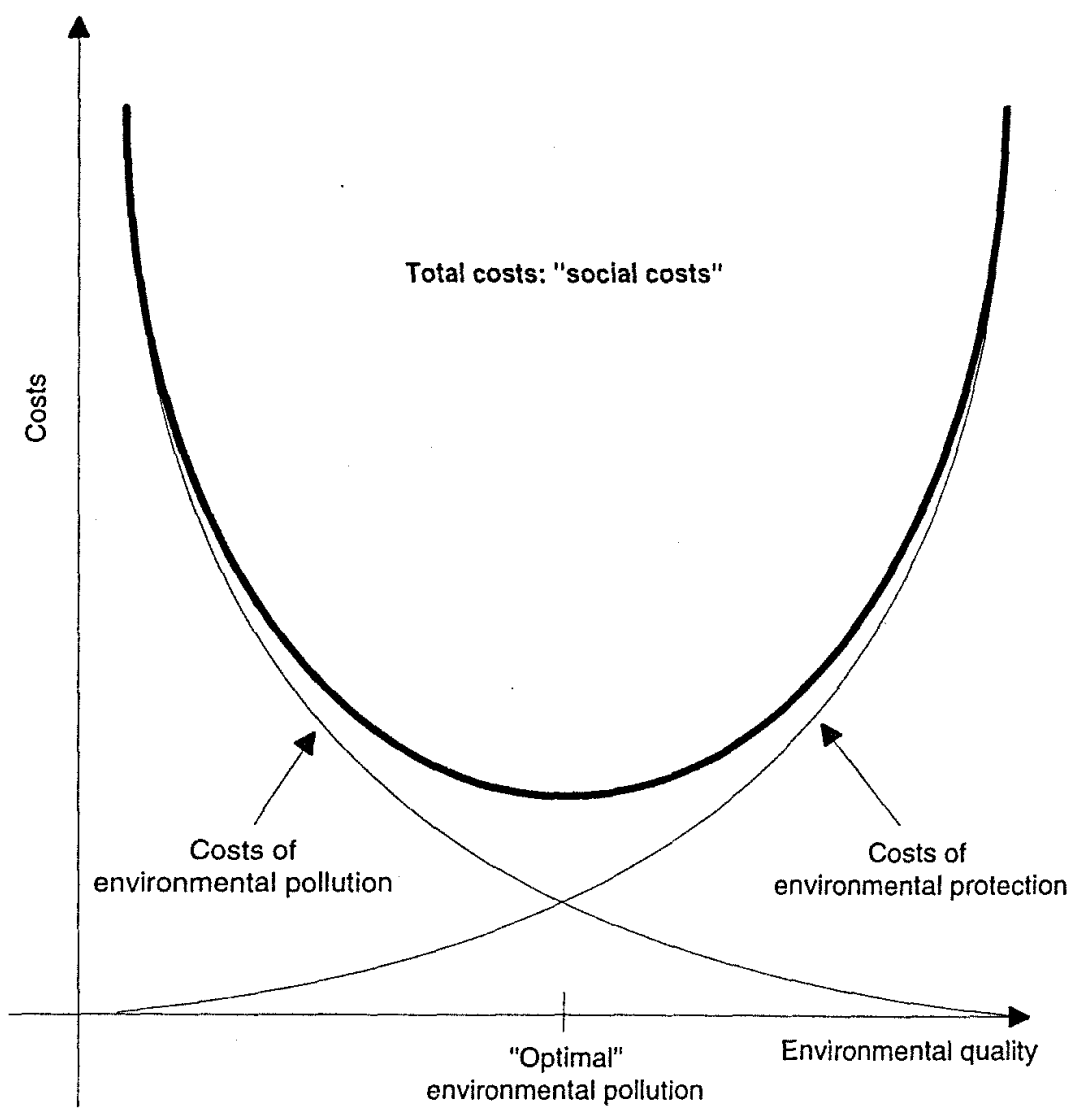

Figure 1. Optimization approach of environmental economics

\subsection{Nature in Economic Theory}

\subsubsection{Internalizing External Costs, Optimizing Welfare}

How can sustainability be integrated into economic science and practice? The current scientific discussion about this subject is very lively and has produced numerous publications $[14,39]$. Simplifying matters, one might say that there are two opposed viewpoints: 'Environmental Economics' attempts to integrate the environment as a particular type of asset or commodity into the neo-classical model. On the other hand, 'Ecological Economics' considers the economic system as part of the global ecological system. In Germany, the first of the two positions is still prevailing. In the Anglo-Saxon and Scandinavian countries as well as in the Netherlands, however, more and more publications of the second group are issued [15].

In the sphere of Environmental Economics, diagnosing the problem usually results in the statement that the lack of a market for environmental goods is the actual cause 
of the desperate situation. Followers of this school of thought say that external costs of environmental pollution would just have to be internalized to arrive at a minimum of social costs in a situation of 'optimal' environmental pollution. The individual approaches suggested to render this idea more precise vary, for instance, with respect to including concerns of nature and interests of future generations. The common scientific background is, however, always the optimization of overall economic welfare [16]. Figure 1 illustrates this problem of optimization.

Nature (including soil) is considered here as a production factor like labour and capital (and technological progress). Utilizing nature leads to wear and tear which as commercial accounting should consistently be applied here - must be taken into account for the periods concerned. The question of how to ascertain external costs is excluded from these theoretical considerations for the time being.

Unfortunately, this very problem of obtaining information entails the crucial theoretical problem: environmental goods are public goods and therefore have no (explicit) price which could reflect their scarcity. To be able to treat them in market terms, either a price or a quantity available must be allocated to them from a metamarket level (regulating policy). As a rule, however, this is precisely the function of the market rather than of the meta-market level. So the market mechanism needs external 'manual' control before it can serve to distribute resources. Several approaches have been suggested for that control and for obtaining the required information; these approaches will be classified by major groups as follows:

Cost function of environmental pollution as related to environmental quality (= imputed damage costs): this approach does not avoid the problem of information and valuation because the risks of environmental pollution cannot be valued without making assumptions concerning coverage, discount rate, value of a life, etc.; all these variables depend on market preferences.

So it appears all the more advisable to follow the alternative approach of directly simulating the demand curve; this means ascertaining the preferences by finding out if maybe more environment is wanted than can at present be demanded because of the lack of actual supply. Such questions referring to the willingness to pay can, for local and limited problems, reveal the structure of preferences with regard to concrete alternatives; they reach their limits, however, where problems have a greater complexity and magnitude. The preferences ascertained by analyses of the willingness to pay will presumably not differ substantially from those reflected by the real market, opinion polls and electoral behaviour, so that only marginal changes can be determined in this way. In addition, the problem of obtaining information is not really avoided because it is shifted to the microlevel.

Does this mean that the solution consists in regulating the quantity permitted rather than the price? Proposals suggesting that tradable pollution permits should be issued following this line. But, considering the above explanations, it is quite obvious that this means shifting the problem of information and valuation to the process of fixing the licence quantities.

For the sake of completeness, the defensive cost approach [17] should be mentioned too, although it is not directly related to a formalized optimization approach. This approach shows the amount currently spent by the society on environmental matters. It has the advantage that processes taking place on the market are included, 
but it also involves a crucial shortcoming: defensive costs are not recorded for the right periods. An abandoned hazardous site from 1954 which is redeveloped today should have been entered on the liabilities side of the accounts in 1954 rather than today when the natural capital is restored. Moreover, this method too, involves considerable problems of delimitation and valuation (integrated environmental protection measures, consequences of follow-up costs, etc.).

The motive underlying these approaches is basically the wish to use the control function of the market for problem-solving and for allocating the scarce resources; this is attempted by transferring decisions as far as possible from the macro-level to the micro-level. In view of the preliminary note explaining that sustainability above all refers to problems of a global, or at least regional, magnitude, this wish must be regarded as not very realistic, although it is perfectly understandable. Really crucial, however, are the assumptions with regard to the substitutability of natural goods and the availability of information.

\subsubsection{Nature as Capital}

With a view to implementing the target of sustainability, two main questions are of interest: what does it mean to treat nature as economic capital, and to what extent does the optimization approach mentioned help to achieve the goal? Six relevant items will be critically examined in the following text [18], but a brief excursion into the discussion of the epistemological bases will be presented first.

3.3.2.1. Excursion: Chaos in the Conception of the World. The following explanations should be considered in the context of a change that occurred in various branches of science in the last century and that is increasingly modifying our (scientific) conception of the world. It is becoming more and more obvious that a straightforward and analytical way of thinking is becoming entangled in 'an endlessly twisted ribbon' [19] interlarded with contradictions, similarities and novel regularities. After familiar bases of epistemology had been relativized in physics and mathematics, representatives of other sciences such as medicine and economics also started discussing these subjects with regard to their respective disciplines and looking for new ways. Some of the principal arguments shall be mentioned below.

One of the fundamental issues is the growing skepticism about the formal drawing up of models that is customary in theoretical economics and involves a great deal of mathematical calculations. Critics point out that scientists - while being enthusiastic about an elegant scientific model - fail to examine the model's ability to explain and solve real problems. In the sense explained by Grohmann, the process of illustrating real problems by way of models may be subdivided into the steps shown in Fig. 2 [20].

Solving formal problems which either cannot be measured or cannot adequately describe reality is a phenomenon referred to as 'Arithmomania' by GeorgescuRoegen [21] and as 'the fallacy of misplaced concreteness' by Daly [22]. The complexity of reality requires its breakup into and reduction to partial problems. This reduction - which in economics is known as the ceteris paribus condition - is justified in many cases where short-term considerations are made. Over the long term, however, partial problems may combine and retroactions lead to sensitive explosive 


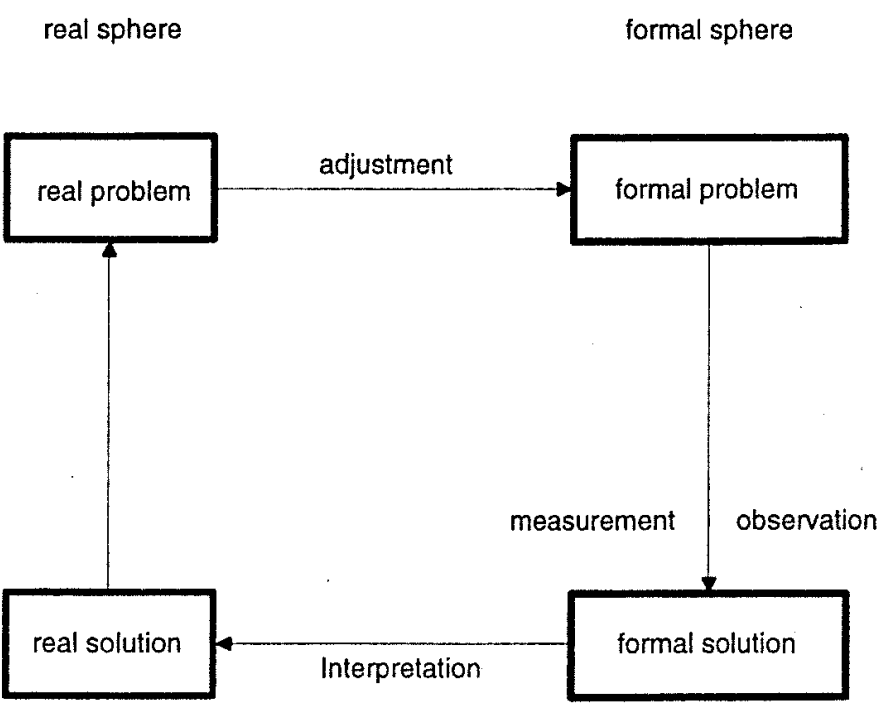

Figure 2. Cognition

processes rather than to linear and stable ones. With such developments, even the slightest measurement errors, which are inevitable anyway, will lead to deterministic chaos; i.e., even if the nature and evolution of the process are precisely known, it is impossible to predict the actual development, which is due to the lack of sufficiently exact knowledge about the initial conditions.

Four other pairs of terms are to supplement the above explanations.

Reversibility - Irreversibility. The second law of thermodynamics - the law of entropy - says that there are processes which can take only one direction and are thus not reversible (for example, the transformation of raw materials into waste).

Quantity - Quality. Qualitative variables will hardly fit into quantitative models; quantifying approaches (for example, valuation in monetary terms) are problematic. Even classical geometry is able to cover in detail just greatly simplified ideal types of geometrical reality. The geometrical forms of a tree, a coastline or a snowflake are very complex and can hardly be represented as a model.

Objective/Absolute - Subjective/Relative. In many cases, neutrality and unambiguity of measurement are rather unrealistic assumptions; subjective definitions of probability or the adjustment of socio-scientific ideal types are striking examples. Subject of observation, observer, and observation are not independent of each other but interconnected. In empirical economic and social research, this very set of problems has long been accepted as a framework condition [23]: In many cases, statistical surveys do not lead to unambiguous results. Data quality determinants such as up-to-dateness, differentiation and precision, but also restrictions of finance and personnel capacities available rather lead to differing statistical data. The wooded area 
of the Federal Republic of Germany is not a fixed value; depending on the scale, method of data collection and definition of wood, highly different results may be produced. Consequently, data quality is never absolute but always relative, and it can be assessed only from the aspect of a specific problem to be solved.

Reductionism - Holism. Many phenomena cannot be explained by decomposing analysis. Difficult and complex matters may arise from the simplest basic elements. The macro-level thus cannot automatically be presented by combining the microelements, which is clearly illustrated by the phenomenon of intelligence. For many processes, such as weather, this is particularly important as no deterministic forecast can be made at the micro-level, while at the macro-level it is definitely possible to determine scopes for solutions, stable conditions and the like. In economics, this conflict between micro-level and macro-level has traditionally been one of the causes for scientific and political dispute.

Even this list of seemingly contrary pairs of terms does not suit reality and the opposites meet upon closer observation: under certain conditions, the notion of subjective probability of the 'Bayesians' will change to the notion of 'objective' probability and so on. Powerful computers which are able to simulate the course of simple but retroactive processes have for some time been employed to deal with these matters. Since such technology has been employed, and maybe even before that time, it has become possible to imagine where gaps exist in the highly specialized structure of science and in what direction one has to move when considering possible consequences [24]. Theory of chaos is the modern summarizing term under which researchers of different disciplines attempt to find structures even in the spheres of reality still unexplored and to furnish new ideas for other methods of problem-solving. The criticism expressed by chaos research with regard to the classical approach of science is both disillusioning and optimistic: on the one hand, it is generally doubted whether the micro-elements of chaotic processes can be predictable at all, while, on the other hand, new structures and regularities are discovered at the macrolevel. Representatives of classical science (rightly) regard such approaches as an attack on their epistemological bases and the value of their scientific findings and consequently make critical comments on them [25].

This excursion is of importance for the following explanations in so far as it aims at creating the necessary sensitivity to the fact that including sustainability involves broadening the horizons of time and region. Sustainability requires shifting from the short-term perspective to long-term views when taking decisions. Considering the above explanations, this demand cannot remain without consequences for the way in which formal (and material) models are drawn up. Thus the question arises, even before the individual items are discussed, whether an optimization approach is a suitable model at all.

3.3.2.2. Substitutability, Technological Progress, Prices. The above inclusion of nature in the pattern of economic thinking is based on the assumption that environmental goods can be treated like goods of produced assets, that is, that they can be substituted for each other and by produced assets or labour. This assumption may be admissible in individual and borderline cases.

If, however, the horizon is broadened to allow global observation, it will become 
obvious that produced assets and labour in turn are results of the use of natural resources. The only input factor of the global and long-term economic and ecological system are natural resources which, over the long term, are limited by solar inputs. Where substitution is included in model considerations, it must be clearly limited. On the whole, the relations must thus be reversed: so far, nature has been considered as a component of the economic system; from the aspect of sustainability, it is obvious that the economic system is an element of the global ecological system and that consequently there are natural limits to the growth of the economic system.

What may be even more important for the target of sustainability is the fact that the individual goods of the environment cannot be substituted for each other [26]. The death of a blue whale cannot be compensated by some reduction of the ozone hole. But this is exactly what is required for the curve of the overall environmental damage: it must be possible to evaluate and add up the individual damages.

As regards raw materials, of which only a limited quantity is available, it is often assumed that the process of their becoming scarcer can be compensated by new technologies. This assumption based on experience made in the past cannot safely be transferred to the future either. It is at least doubtful if the replacing technology will be available in time, at the right place and to the extent required.

A closely connected assumption is the function of prices as indicators of scarcity. It is usually assumed that the raw material markets themselves will regulate the process of resources getting scarce, that is, that prices increase as stocks diminish and, consequently, innovations are initiated in replacing technologies. But it is not clear either whether or not the existing markets do fulfill this function. First, especially the raw material markets are not free of non-market intervention and, second, there is the problem that the price might indicate too late that resources are getting scarce, that is, when it is too late for smoothly switching to a replacing technology.

3.3.2.3. Information, Reversibility, Valuation. After the above reflections, just a rather brief explanation of the informational problem and its relevance is required now. To permit exact assessment in terms of quantity of the impacts an economic activity has on the environment, some problems would have to be solved which are generally considered as unsolvable. The relations between causes and effects are characterized by partly great distances of time and space, overlaps, retroactions and unforeseeable events. Nobody is able to make a sufficiently exact forecast of the effects of $\mathrm{CFC}, \mathrm{CO}_{2}$ or similar problems. Only ranges, scenarios and the like can be given. So the damage cost function in the economic optimization approach - if it were calculated - would vary considerably with respect to shape, height and ascent; thus an optimization is out of the question.

How should damage that is irreversible be treated? An extinguished species cannot be revived. Energy carriers which have been extracted and consumed cannot be regained from the waste thus produced, at least not without an increase in entropy. When shown graphically, the damage function will be vertical in these cases; so a meaningful optimum cannot really be calculated in this borderline case either.

The most difficult issue, however, is the valuation approach: first of all, the quantity and price of assets are not entirely independent of each other so that separate valuation would not really be correct. But what is even more critical in the case of 
natural assets is that there is no consensus on the method of valuation to be applied. This is particularly evident for damage whose occurrence and extent are uncertain and which affects humans, animals or plants. One may have equally long arguments about the value of human life as about the right value to be forecast for a maximum credible nuclear accident or on the interest rate to be applied for discounting the valuated future damage [27].

\section{An Empirical Approach to Environmental-Economic Accounting}

\subsection{Basic Information for the Problem of Decision-Making}

The consequent result of all these critical observations is that an entirely microlevel optimization approach cannot adequately and comprehensively describe the problem of conflicting goals of man and the environment. Daly arrives at the conclusion that sustainability as an economic goal has to be separated from efficiency and just distribution, that is, that first the problem of 'scale' has to be solved before distribution and allocation are dealt with [28]. He demonstrates this by taking $\mathrm{CO}_{2}$ as an example: first a quantity of emissions compatible with the environment on a global scale has to be determined per period; this is not a matter of optimization but the search for strategies safeguarding our very existence. Then problems of distribution (for example, quotas per country) and allocation (for example, tradable permits) have to be solved.

In fact, criticism of an approach adhering to theory is nothing new $[29,40]$; there is still the demand for 'a reorientation of theory with respect to (1) a greater openness towards the idea of an approach with a diversification of tools and (2) a stronger inclusion of deviating framework conditions in the real sphere' [30]. Representatives of the neoclassical approach, however, argue that no principles of action that are relevant to decision-making have so far been derived from the criticism [31].

For setting up an information system on sustainability, this situation is close to a catastrophe. Without an agreement on the problem to be described it is, strictly speaking, not possible to start data collection. Figure 3 again illustrates the theoretical approaches: balancing avoidance costs and either (imputed) damage costs $(u R)$ or the corresponding demand $(N)$. The only values that can empirically be approximated, however, are - at the most - the repair and redevelopment costs actually paid $(u)$ and the actual preventive environmental protection expenditure $(b)$. Nevertheless, it is obviously necessary to collect information relevant to decision-making even before the methodological-theoretical discussion has finally been settled. So the goal must be to elaborate the determinants of a problem of decision-making which is mainly characterized by considerable uncertainty - to the extent that the actual sphere of uncertainty becomes obvious. The basis used here is an approach formalized by Baumol and Oates [32], and in particular by Hueting [33], which aims at an iterative process of decision-making with standard values. Five data types may be considered as determinants:

a. Development of the state of the environment by environmental media and topics; 

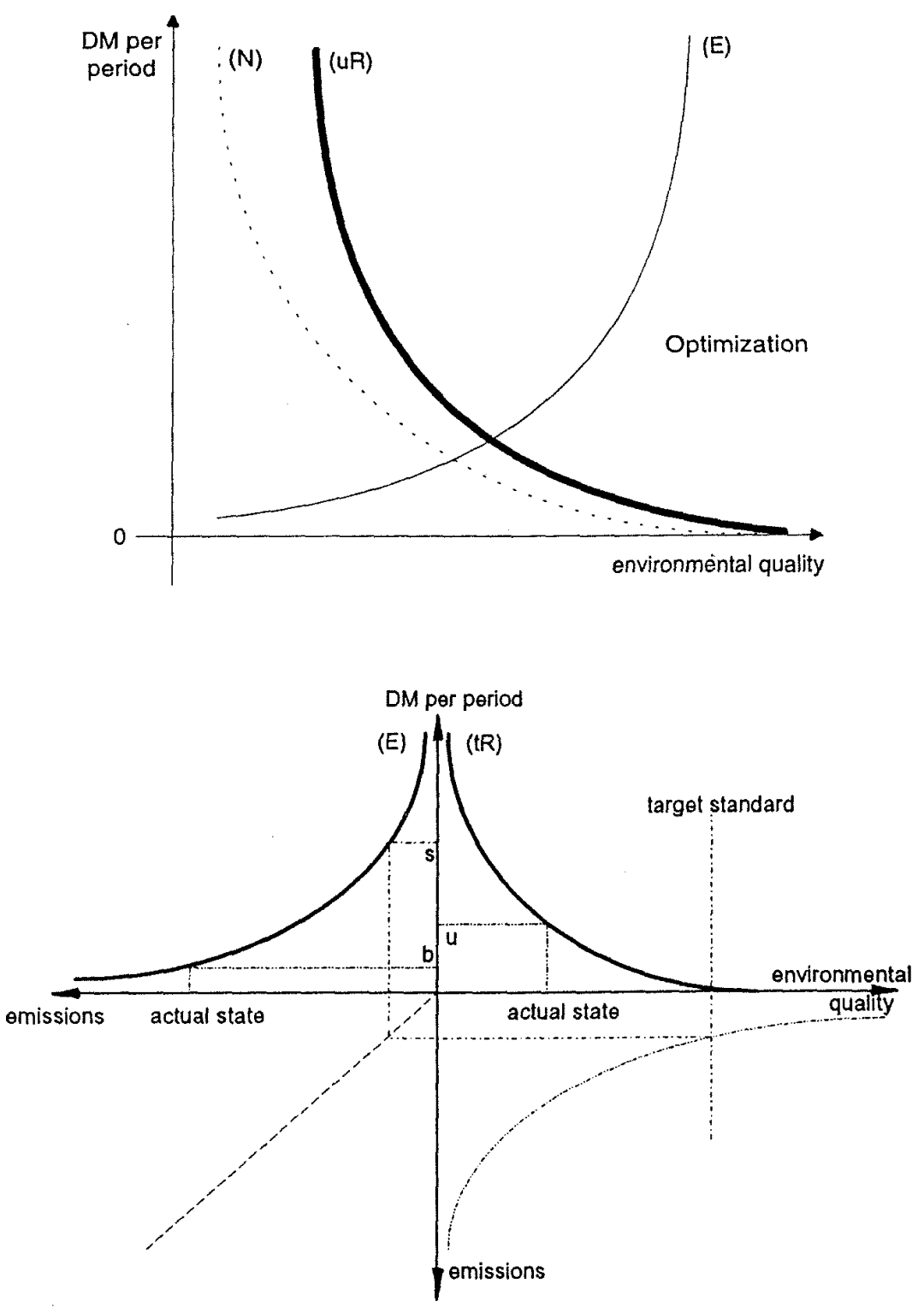

(E) avoidance costs (supply curve)

(tR) repair and redevelopment costs actually paid

(UR) imputed calculative follow-up costs

(N) preference (demand curve)

Figure 3. Alternative optimization approaches versus setting of standards 
b. development of environmental pressures by originating economic sectors;

c. actual expenditure for avoidance and redevelopment;

d. amount of avoidance costs as a function of environmental pressures (Figure 3, function $\mathrm{E}$ );

e. pressure-related target standards.

The first four data types are largely independent of a valuation. The only problems arising with respect to their separate collection concern the empirical method, the efforts required for data collection and the like. On the basis of such information, decisions must be taken concerning the determination of pressure-related standards, target values, etc. It must be made absolutely clear here that the information cannot be expected to provide clear indications suggesting one 'optimal' solution. There will be more or less scope for defining the target values which cannot be delimited and reduced by scientific and neutral assessment or the ascertainment of preferences but only by a social process of decision-making. The problem of information must be regarded as of paramount importance. Solving environmental problems means first of all dealing with incomplete and uncertain information on the consequences of economic action and on future developments. Quite a lot can be done to reduce the scope of decision-making. However, a considerable number of more or less suitable solutions will finally remain, out of which the one must be selected that can be borne most easily by society and that minimizes human intervention. What must be avoided by all means is irreversible damage. This may be achieved - according to Daly - by adhering to the following principles:

1. minimization of human intervention and pressures (guiding principle);

2. consumption of renewable raw materials within the regeneration rate (first input principle);

3. consumption of non-renewable raw materials to the extent corresponding to the development of replacing technologies (second input principle);

4. maximum emissions not exceeding the limit of natural receptivity (output principle).

Although these principles look rather trivial, they are highly restrictive when taken seriously. In particular the third one does not really ensure sustainability. Nobody can predict for which purposes some raw material might be used in future. If one assumes that the human species will exist forever, there will be no satisfactory solution to this problem. Sustainability in the proper sense of the word thus cannot be demanded for finite resources of some raw material. We should endeavour instead to make provisions in time for switching to other technologies. This, in turn, requires early and sufficient investments in the replacing technology. The finiteness of nonrenewable raw materials, on the other hand, is not primarily a matter of ecology but first of all an economic issue, in so far as a satisfactory solution from the environmental aspect is not really of top priority.

As regards the types of information not included in the above list of the five most important data types, it should be mentioned that

f. damage costs (actual or imputed); 
g. demand for environmental goods; and

h. expertise

may be very useful for finding a satisfactory solution if they are available with adequate data quality. An integrative system of environmental information should follow this logic and supply such information in an appropriate way. This would ensure that relevant sets of data are available for situations where cost-benefit analyses are effective.

\subsection{Sustainable National Income}

In technical and public discussions it is frequently demanded that a national income adjusted for environmental damage (Sustainable Income, Green National Product, Green GDP, etc.) be calculated. In view of above considerations, a first summary may be given on this topic: it is generally expected that such a highly aggregated value could help to advance and facilitate decision-making in the conflict between environment and growth. The statistical and objective recording and valuation of all benefits and shortcomings is expected to eventually cut the Gordian knot and give environmental policy the importance it deserves over the long term. In the light of the above reflections, it is obvious that such expectations cannot be met. There is no adjusted váiõå iæ éîcome ánd growth that could objectively be calculated. It is thus impossible to obtain an a priori Green National Product that could be calculated prior to and with the aim of taking a decision on standards and qualitative targets.

Especially Hueting and the United Nations [34] advocate the calculation of a corrective value supplementing the national product. Hueting clearly bases his considerations on the basic information mentioned in the previous section; his justification for choosing the 'avoidance cost approach' as the core element corresponds to the reasons given here. The approach followed by the United Nations is similar in this respect, although it presents several different valuations. The major steps of the Hueting and UN approaches correspond to the concept presented here. As regards the Green National Product, however, they go beyond the proposals made in this contribution. Hueting considers 'sustainable standards' as values that can be determined in an objective and scientific way. This opinion must be rejected here. In the case of $\mathrm{CO}_{2}$, for instance, Hueting takes the natural receptivity as a basis. Closer examination shows, however, that this uptake capacity can be estimated on a global scale only - if estimation is possible at all - while the Dutch, German or Brazilian share can be ascertained only by solving a problem of distribution [35].

In addition, there are uncertainties concerning the cause/effect relations: even if a qualitative goal is found for the side of the current state of the environment, standards have still to be set for the originating side.

In other words, setting national standards for individual types of pressures cannot be the task of statistics. Actually, standards are the real target values; to determine these standards by international and national negotiations, statistics has to provide adequate and neutral information. After all the standards have definitely been fixed, it is of course possible to calculate also an a posteriori Green National Product ${ }^{1}$. For

'The exact denomination is 'Green Domestic Product'; for its calculation, see Stahmer [37]. 
this purpose, the avoidance costs additionally required have to be computed first (this is s-b in Figure 3). To avoid double counts, the repair and redevelopment costs actually paid have to be subtracted from this value ( $u-0$ in Figure 3 ). The balance of the two values - similar to depreciation at the business level - equals the additional costs required for maintaining the natural assets. These costs essentially depend on the standards set and - in the sense presented here - thus are not values predetermined for the process of decision-making but rather the results of that process. In this sense, it is of course possible to calculate the avoidance costs for alternative standards too.

Caution is advisable also from another aspect: the statistical calculation of an avoidance cost curve can only be the first step in an iterative series where it is not considered how an actual integration of external effects is received and reacted to by the market. Estimating the actual, final burden caused by additional levies, licences and the like moreover requires simulating the market by relevant models.

\subsection{Limits of Informational Growth}

As is shown by the initial quote of Jevons, the economic approach includes a specific attitude towards the informational problem: on the one hand, (nearly perfect) information at the micro-level or, at least, at the macro-level is an indispensable prerequisite for achieving an optimum. On the other hand, obtaining such information is a matter of technology (including statistics).

Looking at the problem as a whole, however, one will again be faced with the limits of growth. The economic growth of the last few decades has also led to a substantial increase in the demand for information. The resulting informational industry (including the media) in turn has contributed to informational growth. Many authors believe that the change from the industrial society to the informational society has already taken place. This means that, in addition to environmental pollution, the continuously and rapidly growing flood of information is a problem and characteristic of today's Western societies. Consequently, the individual piece of information decreases in value and the gap between information and knowledge is growing. 'The gap between the power of knowing in advance and the power of action creates a new ethical problem. Acknowledging ignorance will then become the reverse side of the duty to know ...' [37].

Consequently, it is essential to be aware of this relation between the problems of environment and information when setting up an informational system. For every piece of information required in addition, it has to be checked whether the decision envisaged might already be taken on the basis of the information available anyway. If this is not the case, it should further be checked

- whether available data have shortcomings in terms of form or contents that can be eliminated,

- whether the data demand can be met at all and

- what is the 'most economical' solution for new data.

The approach to the Environmental-Economic Accounting in Germany is generally based on the assumption that the first case frequently applies, that is, there is no 
lack of information, but the information is not available in a form that suits the problem. Data are either not available at all or not accessible to the public, they may be too specialized and isolated or not comparable in terms of methodology. This means that, before any valuation approach can be implemented, practical problems have to be solved concerning data collection and the organization of activities between several agencies involved, for example, between the Federation and the federal states (Länder). Accomplishing this task - where it is not completely impossible - often proves to be highly time-consuming.

\section{References}

[1] Robinson, J.: Economic Philosophy, Chicago 1962, p. 66

[2] Radermacher, W.: Konzept für eine Umweltökonomische Gesamtrechnung des Statistischen Bundesamtes, in Wirtschaft und Statistik, No. 7, 1992, p. $411 \mathrm{ff}$.

[3] Inquiry Commission of the 11th German Bundestag "Vorsorge zum Schutz der Erdatmosphäre": Schutz der Erde: eine Bestandsaufnahme mit Vorschlägen zu einer neuen Energiepolitik, Ed.: German Bundestag, Public Relations Section, Bonn 1990, Vol. 2, p. 973.

[4] Brundtland Report (World Commission on Environment and Development): Our common future, Oxford 1987.

[5] Pearce, D., Babier, E., and Barkandya, A.: Sustainable Development - Economics and Environment in the Third World, Brookfield 1990.

[6] Hicks, J.R.: Value and capital, Oxford 1950, p. 172.

[7] Gore, A.: Wege zum Gleichgewicht, Boston 1992.

[8] Zimmermann, H.: Ökonomische Aspekte globaler Umweltprobleme, Zeitschrift für angewandte Umweltforschung, No. 3, 1992, p. $310 \mathrm{ff}$.

[9] Naess, A.: Ecology, community and lifestyle, New York 1989.

[10] Meadows, D. and Randers, J.: Die neuen Grenzen des Wachstums, Stuttgart 1992.

[11] Krelle, W.: Wirtschaftswachstum und Umweltschutz: ein Zielkonflikt?, Lecture held at the Academy of the Federal Ministry of Defence in Mannheim on 4 November 1992.

[12] Eilingsfeld, H.: Der sanfte Wahn - Okologismus Total, Mannheim 1989.

[13] Jänicke, M., Mönch, H. and Binder, M.: Umweltentlastung durch industriellen Strukturwandel?, Berlin 1992.

[14] Beckenbach, F. (Ed.): Die ökologische Herausforderung für die ökonomische Theorie, Marburg 1991.

[15] Costanza, R. (Ed.): Ecological economics - the science and management of sustainability, New York 1991.

[16] Wicke, L.: Umweltökonomie, München 1989.

[17] Leipert, Ch.: Die heimlichen Kosten des Fortschritts, Frankfurt 1989.

[18] Victor, P.A., Kay, J.J. and Ruitenbeek, H.J.: Economic, ecological, and decision theories: indicators of ecological sustainable development, Ed.: Canadian Environmental Advisory Council, Ottawa 1991.

[19] Hofstadter, D.R.: Gödel, Escher, Bach - ein endlos geflochtenes Band, Darmstadt 1988.

[20] Grohmann, H.: Vom theoretischen Konstrukt zum statistischen Begriff - Das Adäquationsproblem, in Allgemeines Statistisches Archiv, Vol. 69, 1985, p. 1 ff.

[21]. Georgescu-Roegen, N.: The Entropy Law and the Economic Process, London 1971.

[22] Daly, H.E. and Cobb, J.B.: For the common good, London 1989.

[23] Chlumsky, J. (ed.): Qualität statistische Daten, Wiesbaden, 1993.

[24] Prigogine, I. and Stengers, I.: Order out of Chaos, New York 1984.

[25] Michel, K.M. and Spengler, T. (Eds.): Kursbuch Das Chaos, Berlin 1989. 
[26] Tappeiner, U.: Darstellung und Bewertung der Wechselbeziehungen zwischen dem Wirtschaftsprozeß und dem Zustand der Umwelt - Analyse aus Sicht der Ökologie, Stuttgarter Input-Output-Workshop, 1992.

[27] Drepper, F.R. and Mansson, B.A:: Intertemporal valuation in an unpredictable environment, in Ecological Economics, 1993, p. $43 \mathrm{ff}$.

[28] Daly, H.E.: Allocation, distribution, and scale: towards an economics that is efficient, just, and sustainable, in Ecological Economics, 1992, p. $185 \mathrm{ff}$

[29] Hansmeyer, K.-H.: Ökonomische Anforderungen an die staatliche Datensetzung für die Umweltpolitik und ihre Realisierung, in Marktwirtschaft und Umwelt, Ed. Wegehenkel, L., Tübingen 1981, p. $6 \mathrm{ff}$.

[30] Gawel, E.: Die mischinstrumentelle Strategie in der Umweltpolitik: Ökonomische Betrachtungen zu einem neuen Politikmuster, in Jahrbuch für Sozialwissenschaft, Vol.43, 1992 , p. $267 \mathrm{ff}$.

[31] Hourcade, J.-C., Salles, J.-M. and Théry, D.: Ecological economics and scientific controversies. Lessons from some recent policy making in the EEC, in Ecological Economics, No. 6, 1992 , p. $211 \mathrm{ff}$.

[32] Baumol, W.-J. and Oates, W.-E.: The theory of environmental policy, Cambridge 1988.

[33] Hueting, R., Bosch, P. and de Boer, B.: Methodology for the calculation of Sustainable National Income, Voorburg 1991.

[34] UNSO (Statistical Office of the United Nations): SNA handbook on integrated environmental and economic accounting, Interim version, New York 1992.

[35] Barrett, S.: Reaching a $\mathrm{CO}_{2}$-emission limitation agreement for the Community: implications for equity and cost-effectiveness, in European economy - the economics of limiting $\mathrm{CO}_{2}$ emissions, Ed.: Commission of the European Communities, Special edition No. 1, Brussels 1992.

[36] Jonas, H.: Das Prinzip Verantwortung, Frankfurt, p. 28.

[37] Stahmer, C.: Integrierte Volkswirtschaftliche und Umweltgesamtrechnung - Überblick über die Konzepte der Vereinten Nationen, in Wirtschaft und Statistik, No. 9, 1992, p. $577 \mathrm{ff}$.

[38] Bolleyer, R., Radermacher, W. et al.: Aufbau der Umweltökonomischen Gesamtrechnung Ein Bericht aus der Werkstatt, Wirtschaft und Statistik, No. 2, 1993, p. $138 \mathrm{ff}$.

[39] Hampicke, U.: Ökologische Ökonomie, Opladen 1992.

[40] James, D.E., Nijkamp, P. and Opschoor, J.B.: Ecological sustainability and economic development, in Economy and Ecology: Towards Sustainable Development, Ed. Archibugi, F. and Nijkamp, P., Dordrecht 1989, p. 27 ff.

Walter Radermacher studied economics at the universities of Aachen and Münster. He has been a staff member of the Federal Statistical Office since 1978, initially working on statistics of distributive trade and the hotel and restaurant industry. Since 1985, Mr. Radermacher has been in charge of research and development in the field of Geographical Information Systems and Remote Sensing; from 1991 on he has also been responsible for setting up the System of Environmental-Economic Accounting. 